\title{
Usage of Cox-Regression Model for Forecasting of Survival Rate in Patients with the Early Stage of Non-Small Cell Lung Cancer
}

\author{
Oleksey P. Kolesnik ${ }^{1}$, Anatoliy I. Shevchenkoㄹ, Yuriy E. Lyakh², Vitaliy G. Gurianov², \\ Pavel A. Alyoshechkin ${ }^{2}$ \\ ${ }^{1}$ Department of Oncology, Zaporizhzhya State Medical University, Zaporizhzhya, Ukraine \\ ${ }^{2}$ Department of Medical Biophysics, Medical Informatics and Biostatistics, M. Gorky Donetsk National Medical \\ University, Donetsk, Ukraine \\ Email: kap kan@mail.ru, ai shevchenko@ukr.net, liakh@dsmu.edu.ua, vitaliy.gurianov@dsmu.edu.ua, \\ alyoshechkin-pavel@rambler.ru
}

Received 1 February 2014; revised 1 March 2014; accepted 8 March 2014

Copyright (C) 2014 by authors and Scientific Research Publishing Inc.

This work is licensed under the Creative Commons Attribution International License (CC BY). http://creativecommons.org/licenses/by/4.0/ (c) (i) Open Access

\begin{abstract}
In the past decades a lot of investigations were focused on searching for more accurate markers of lung cancer progression. Researchers indicate that molecular markers may be useful in forecasting of treatment outcome and overall survival rate in patients with non-small cell lung cancer. The aim of our research was to create a forecasting model in order to identify patients with stage I-II of non-small cell lung cancer and dismal prognosis. Our research covered 254 patients with the early stage of non-small cell lung cancer who underwent a cure from June 2008 till December 2012 in the Department of Thoracic Surgery of Zaporizhzhia Regional Clinical Oncologic Dispensary. Surgery was performed for all patients. Adjuvant chemotherapy was performed for 101 patients. In order to carry out multivariate Cox-regression analysis, STATISTICA 6.0 (StatSoft Inc.) program was used. The most significant from 39 variables were selected (tumor size, histological form of tumor, volume of surgical intervention, volume of conducted lymph node dissection, Ki-67 expression, EGFR expression, E-cadherin expression). We propose the computer system which can forecast survival rate in patients with the early stage of non-small cell lung cancer.
\end{abstract}

\section{Keywords}

Forecasting Model; Survival Rate; Non-Small Cell Lung Cancer 


\section{Introduction}

It is well-known that lung cancer is subdivided into non-small cell lung cancer (NSCLC) which makes approximately 80\% - 90\% from all malignant lung tumors and small cell lung cancer which makes $10 \%$ - 20\% respectively. Fundamental type of treatment for patients with the early-stage of NSCLC is surgery. However, 22\% $50 \%$ of patients have local recurrences after surgery and $48 \%$ - $78 \%$ of patients have distant metastases [1]-[5].

In the past decades a lot of investigations were focused on searching for more accurate markers of lung cancer progression. Researchers indicate that molecular markers may be useful in forecasting of treatment outcome and overall survival rate in patients with NSCLC [4] [6]-[9]. Currently large number of markers are offered for patients with NSCLC but none of them shows its high significance in clinical practice [6]. Further research of molecular forecasting markers is needed. By that time their significance in routine practice is not adequate [3].

The aim of our research was to create a forecasting model in order to identify patients with stage I-II of NSCLC and dismal prognosis.

\section{Materials and Methods}

Our research covered 254 patients with the early stage of NSCLC who underwent a cure from June 2008 to December 2012 in the Department of Thoracic Surgery of Zaporizhzhia Regional Clinical Oncologic Dispensary. Surgery was performed for all patients. Adjuvant chemotherapy was performed for 101 patients.

In order to carry out multivariate Cox-regression analysis STATISTICA 6.0 (StatSoft Inc.) program was used. 39 variables (sex, age, height, weight, body mass index (BMI), BMI (categorized index), localization of the tumor and its clinical form (lung, lobes of the lung, central/peripheral lung cancer), tumor size, tumor size (categorized index), criterion "T", criterion "N", stage of disease, histological and morphological form of tumor differentiation, presence of necrosis in tumor, infiltration of visceral pleura, volume of surgical intervention, volume of conducted lymph node dissection, fact of intraperitoneal delegation of lung blood vessels, conducting of adjuvant radiotherapy and chemotherapy, complaints on weakness, loss of appetite, loss of body weight, cough, shortness of breath, chest pain, hemoptysis, hyperthermia, detection of malignant lung neoplasm during prophylactic examination, Ki-67 expression (categorized index), CD31/CD34 expression, Her2-neu expression, EGFR expression, p53 expression, E-cadherin and pan-cytokeratin expression) were used. The most significant of them were selected. Such selection was performed by means of univariate analysis with retaining of variables that have significance level $\mathrm{p}<0.1[10]$.

\section{Results}

All obtained after univariate analysis variables and their characteristics are present in Table 1.

Research on collinearity (independence) was performed after ANOVA. The variables which dependent on each other were excluded. Only the most significant markers were left. Reverse selection of variables was used. First model was calculated with all possible predictive variables and then re-calculated after removing of variability with the least significant interconnection, with response variable (survival rate). The process lasted until the model contained only statistically significant variables (Table 2).

Survival rate based on these prognostic factors can be calculated for any patient with the early stage of NSCLC.

Let us consider some examples:

Example 1. Patient G., 71-year-old man. Received institutional treatment at Department of Thoracic Surgery of Zaporizhzhia Regional Clinical Oncologic Dispensary between August 26, 2008 and September 17, 2008.

Diagnosis: Central cancer of right lung superior lobe. pT2N0M0. Stage IB.

Concomitant diseases: Coronary heart disease: atherosclerotic cardiosclerosis. Circulatory inefficiency stage II. Obliterating atherosclerosis of the lower extremities.

Clinical examination data: Considered complaints on pain in the right side of the chest, shortness of breath and cough since February 2008. At clinic were performed such examination as: abdominal ultrasound: ultrasound signs of urine acid diathesis; CT-scan of lung: in right lung superior lobe near the root of lung, peribronchially, relatively to proximal bronchus, $49 \times 29 \mathrm{~mm}$ neoplasm was marked. Enlarged lymph nodes: paratracheal up to $10 \mathrm{~mm}$, bifurcation up to $13 \mathrm{~mm}$, bronchial (right side) up to $13 \mathrm{~mm}$, bronchopulmonary (right side) up to 13 mm; Fiber-optic bronchoscopy: proximal bronchus with peribronchial tumor growth; Cytological conclusion No7153: moderately differentiated squamous cell carcinoma; Spirography: 1st degree respiratory failure. 
Table 1. Variables and their characteristics after univariate analysis.

\begin{tabular}{|c|c|c|c|c|c|}
\hline No & Variable & Min & Max & $\begin{array}{l}(M \pm m)^{*} \\
(\% \pm m \%)^{* *}\end{array}$ & Significance level, $\mathrm{p}$ \\
\hline \multirow{2}{*}{1} & \multirow{2}{*}{ Sex } & \multicolumn{2}{|c|}{ Men } & $83.9 \% \pm 2.3 \%$ & \multirow{2}{*}{0.93} \\
\hline & & \multicolumn{2}{|c|}{ Women } & $16.1 \% \pm 2.3 \%$ & \\
\hline 2 & Age, years & 34 & 77 & $60.7 \pm 0.51$ & 0.89 \\
\hline 3 & Height, cm & 150 & 191 & $171.4 \pm 0.46$ & 0.89 \\
\hline 4 & Weight, kg & 46 & 115 & $73.7 \pm 0.84$ & 0.56 \\
\hline 5 & BMI & 16.9 & 38.9 & $25.1 \pm 0.28$ & 0.54 \\
\hline \multirow{2}{*}{6} & \multirow{2}{*}{ BMI (categorized) } & \multicolumn{2}{|c|}{$<30 \mathrm{mg} / \mathrm{m}^{2}$} & $83.9 \% \pm 2.3 \%$ & \multirow{2}{*}{0.33} \\
\hline & & & & $16.1 \% \pm 2.3 \%$ & \\
\hline \multirow{2}{*}{7} & \multirow{2}{*}{ Localization, lung } & \multicolumn{2}{|c|}{ Right } & $49.6 \% \pm 3.1 \%$ & \multirow{2}{*}{0.55} \\
\hline & & & & $50.4 \% \pm 3.1 \%$ & \\
\hline \multirow{3}{*}{8} & \multirow{3}{*}{ Localization, lobe of lung } & \multicolumn{2}{|c|}{ Upper } & $62.6 \% \pm 3.0 \%$ & \multirow{3}{*}{0.91} \\
\hline & & & & $3.5 \% \pm 1.2 \%$ & \\
\hline & & & & $33.9 \% \pm 3.0 \%$ & \\
\hline \multirow{2}{*}{9} & \multirow{2}{*}{ Localization } & \multicolumn{2}{|c|}{ Central } & $39.8 \% \pm 3.1 \%$ & \multirow{2}{*}{0.48} \\
\hline & & \multicolumn{2}{|c|}{ Peripheral } & $60.2 \% \pm 3.1 \%$ & \\
\hline 10 & Tumor size, cm & 1.2 & 14 & $4.88 \% \pm 1.13$ & $<0.001$ \\
\hline \multirow{2}{*}{11} & \multirow{2}{*}{ Tumor size, (categorized) } & \multirow{2}{*}{\multicolumn{2}{|c|}{$\begin{array}{l}\geq 3 \mathrm{~cm} \\
<3 \mathrm{~cm}\end{array}$}} & $78.0 \% \pm 2.6 \%$ & רח0 0 ר \\
\hline & & & & $22.0 \% \pm 2.6 \%$ & 0.002 \\
\hline & & & & $12.6 \% \pm 2.1 \%$ & \\
\hline 12 & Criterion "T" & & & $83.5 \% \pm 2.3 \%$ & 0.31 \\
\hline & & & & $3.9 \% \pm 1.2 \%$ & \\
\hline 13 & Critarion "N" & & & $71.3 \% \pm 2.8 \%$ & 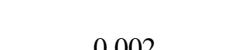 \\
\hline 13 & Chilenioni in & & & $28.7 \% \pm 2.8 \%$ & 0.002 \\
\hline 14 & Ctora & & & $52.4 \% \pm 3.1 \%$ & 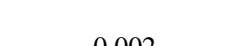 \\
\hline 14 & Stage & & & $47.6 \% \pm 3.1 \%$ & 0.002 \\
\hline 15 & Histological form & & & $58.7 \% \pm 3.1 \%$ & 001 \\
\hline 10 & . & & lous & $41.3 \% \pm 3.1 \%$ & 0.01 \\
\hline & & & & $23.2 \% \pm 2.6 \%$ & \\
\hline 16 & Morphological differentiation & & & $50.8 \% \pm 3.1 \%$ & 0.43 \\
\hline & & & & $26.0 \% \pm 2.8 \%$ & \\
\hline 17 & Droconco of nocrocic & & & $55.5 \% \pm 3.1 \%$ & 044 \\
\hline 17 & Presence or necrosis & & & $44.5 \% \pm 3.1 \%$ & 0.44 \\
\hline 18 & Infiltration of visceral nloura & & & $57.5 \% \pm 3.1 \%$ & 048 \\
\hline 10 & . & & & $42.5 \% \pm 3.1 \%$ & 0.40 \\
\hline 10 & Volume of curraical intoryontion & & & $63.0 \% \pm 3.0 \%$ & 0007 ר \\
\hline 19 & vointine or surgical interventionin & Pne & omy & $37.0 \% \pm 3.0 \%$ & 0.002 \\
\hline 20 & Volume of conducted lymph node & & & $31.9 \% \pm 2.9 \%$ & 0007 \\
\hline 20 & dissection & & & $68.1 \% \pm 2.9 \%$ & 0.007 \\
\hline 21 & Intraperitoneal delegation of lung blood & & & $87.8 \% \pm 2.1 \%$ & 0018 \\
\hline & vessels & & & $12.2 \% \pm 2.1 \%$ & 0.010 \\
\hline 2 & 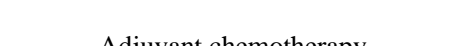 & & & $60.2 \% \pm 3.1 \%$ & 0.01 \\
\hline 22 & 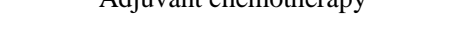 & & & $39.8 \% \pm 3.1 \%$ & 0.31 \\
\hline
\end{tabular}




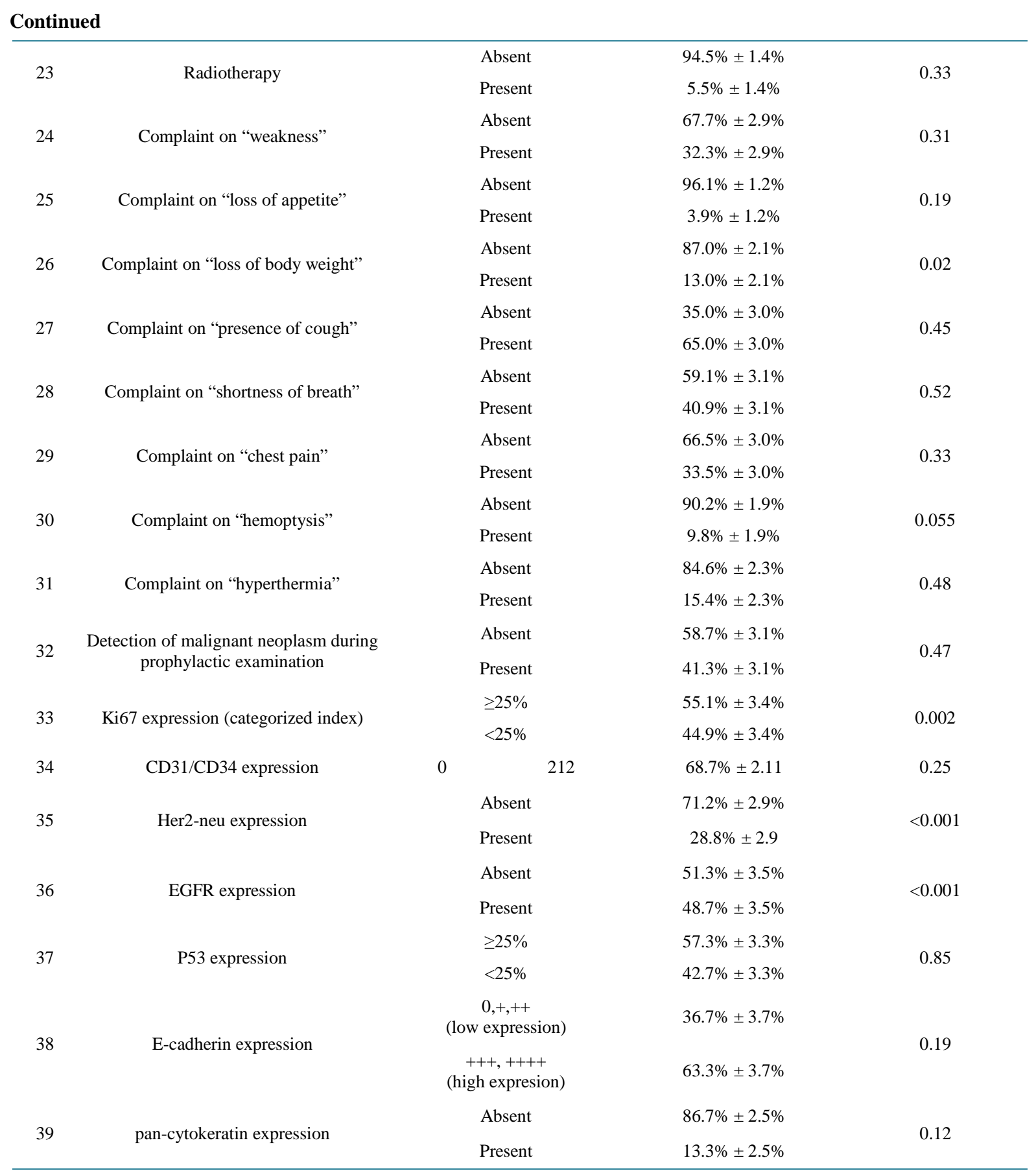

Note: $\mathrm{p}$ —connection with survival rate (censored). ${ }^{*} \mathrm{M}$ (average); $\mathrm{m}$ (standart error); ${ }^{* *} \mathrm{~m} \%$ (standart error of proportions).

After examination surgery was performed: right-sided pneumonectomy, lymph node dissection D1. Histological conclusion: No 33959-70: non-keratinizing squamous cell lung carcinoma with foci of necrosis. In bronchus and lymph nodes at the operating region the malignant growth elements were not found (pT2N0M0 G2).

Thus, prognostic factors significance is as follows:

Tumor size $5 \mathrm{~cm}-5$ points;

Histological type of tumor: squamous cell carcinoma-2 points;

Volume of surgical intervention: pneumonectomy-2 points;

Lymph node dissection volume: D1—1 point; 
Table 2. Statistically significant variables of forecasting model.

\begin{tabular}{cccccc}
\hline Variable & Coefficient $(\beta)$ & Standard error & Significance level, $\mathrm{p}$ & OR & $95 \%$ CI \\
\hline Tumor size, cm & 0.14 & 0.06 & 0.021 & 1.16 & $1.06-1.76$ \\
Histological form & -0.79 & 0.24 & $<0.001$ & 0.45 & $0.04-0.29$ \\
$\begin{array}{c}\text { Volume of surgical } \\
\text { intervention }\end{array}$ & 1.16 & 0.29 & $<0.001$ & 3.19 & $3.13-24.95$ \\
$\begin{array}{c}\text { Volume of conducted } \\
\text { lymph node dissection }\end{array}$ & -1.21 & 0.32 & $<0.001$ & 0.29 & $0.04-0.47$ \\
Ki-67 expression & 0.64 & 0.28 & 0.020 & 1.91 & $1.62-10.69$ \\
EGFR expression & 1.68 & 0.34 & $<0.001$ & 5.40 & $2.03-16.25$ \\
E-cadherin expression & -1.07 & 0.29 & $<0.001$ & 0.34 & $0.09-0.52$ \\
\hline
\end{tabular}

Ki-67 expression: $17 \%-1$ point;

EGFR expression: “+”-1 point;

E-cadherin expression: “++" -2 points.

Figure 1 shows forecasting of survival rate in patient G. As it may be seen, survival rate median is not reached, patient's chance to five-year survival rate is more than $60 \%$. Control period of observation-June 01 , 2013, patient is alive. Period of observation is 64 months.

Example 2. Patient M., 66-year-old man. Received institutional treatment at Department of Thoracic Surgery of Zaporizhzhia Regional Clinical Oncologic Dispensary between July 14, 2010 and August 02, 2010.

Diagnosis: Peripheral cancer of right lung superior lobe. pT2N0M0. Stage IB.

Clinical examination data: Considered complaints on shortness of breath and cough near 2 months ago. At clinic were performed such examinations as: X-ray chest examination: in rear segment of superior lobe of right lung marked $6 \times 6,5 \mathrm{~cm}$ extensive tuberous neoplasm with path to the root of lung. Also, subpleurally in the right root of the lung determined enlarged bronchial-pulmonic lymph nodes; CT-scan: in S2 of right lung viewed $40 \times 40 \mathrm{~mm}$ peripheral neoplasm with luminous contours. Also, in S10 of lower lobe marked $21 \times 26$ $\mathrm{mm}$ neoplasm. Mediastinal lymph nodes were not enlarged; Abdominal ultrasound: abdomen pathology is not found; Fiber-optic bronchoscopy: without intraluminal pathology;

After examination surgery was performed: right-side upper lobectomy with lymph node dissection D1. Histological conclusion No 22729-34: non-small cell lung carcinoma with necrosis. In bronchus and lymph nodes from operating region, the malignant growth elements were not found (pT2N0M0 G3).

Thus, prognostic factors significance is as follows:

Tumor size $6 \mathrm{~cm}-6$ points;

Histological type of tumor: large cell carcinoma—1 point;

Volume of surgical intervention: upper lobectomy -1 point;

Lymph node dissection volume: D1-1 point;

Ki-67 expression: $100 \%-2$ points;

EGFR expression: “+++"-2 points;

E-cadherin expression: “+”-1 point.

Figure 2 shows forecasting of survival rate in patient $\mathrm{M}$. As it may be seen, survival rate median equals 10 11 months; patient's chance to five-year survival rate is almost equals $0 \%$. Indeed patient's survival rate was 11 months and he died from the progression of disease.

\section{Discussion}

Several studies were devoted to prognostic factors search [4] [7]-[9] [11]. Clinical, morphological, genetic factors have been researched as prognostic factors for patients with NSCLC.

It is noted that the most significant factors are the follows: overall clinical status of the patients, tumor size, vascular invasion, poor differentiation and presence of necrosis in the tumor, distant extrapulmonary metastases, type of conducted chemotherapy, number of white blood cells, level of CYFRA 21-1, Ca 125, Ca 15-3, and Ca 72-4 [2] [4] [7] [8] [10]-[13]. In our research 39 prognostic markers of 254 patients were examined. At the same time independent prognostic factors selected by Cox-regression analysis were: size and histological type of tumor, type of surgical intervention, volume of conducted lymph node dissection. 


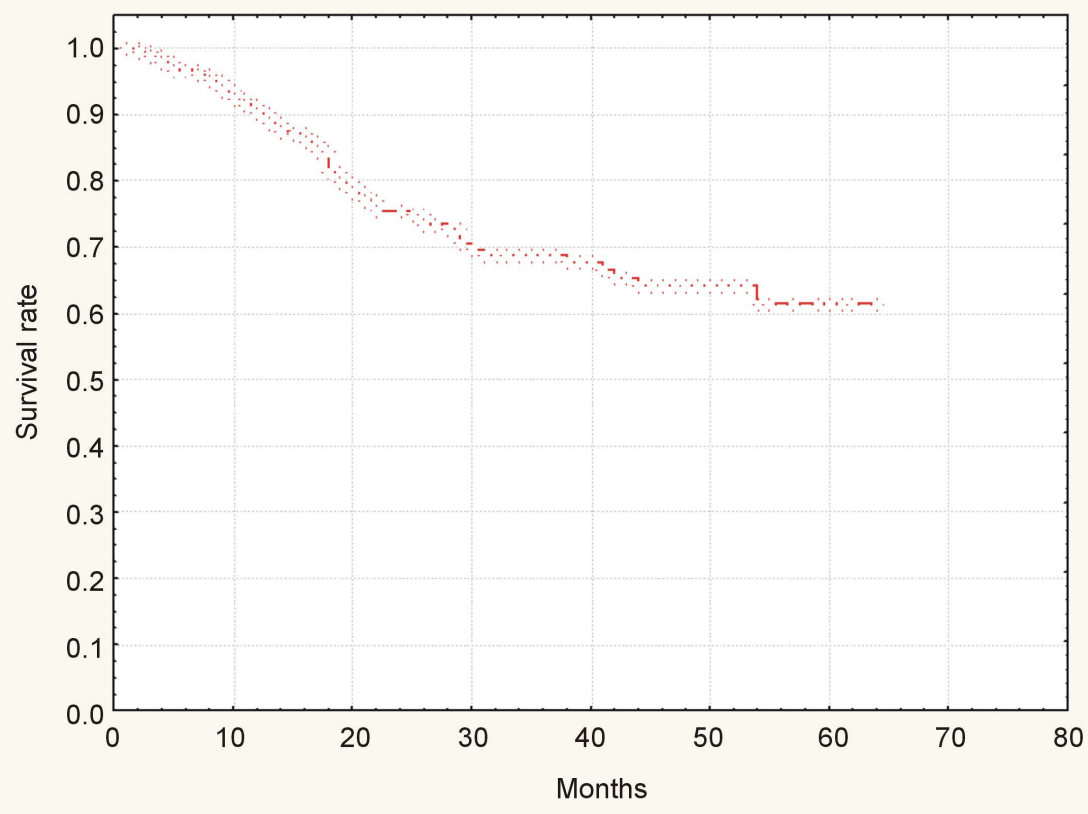

Figure 1. Patient G. forecasting of survival rate.

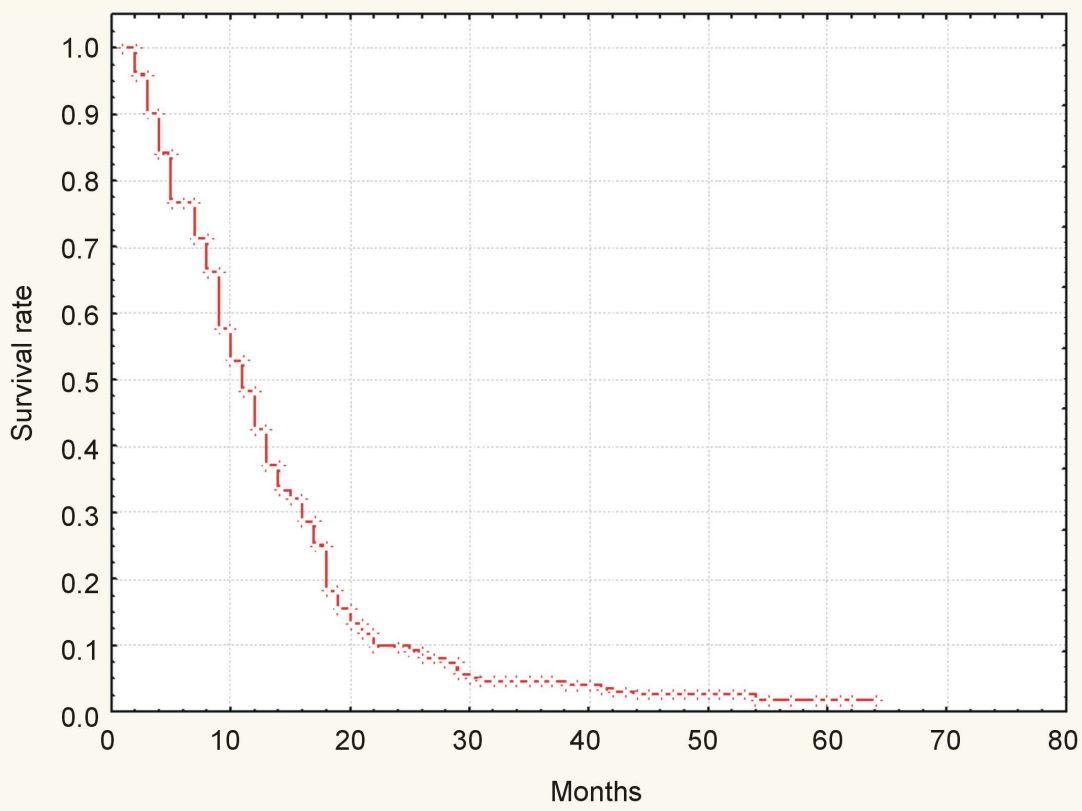

Figure 2. Patient M. forecasting of survival rate.

Among the molecular and genetic markers, such factors were prognostically significant: p53, factor 8, erb-b2, Cd-44, retinoblastoma recessive gene, cyclin E, cyclin D1, methylation DAPK, IL-10 expression, p21. Also genetic prognostic markers have been identified—genes Wnt3a, Erbb3, LSK, Rnd3 [2] [5] [6]. We have demonstrated the prognostic role of Ki-67, EGFR and E-cadherin expression. Other factors that were analyzed showed no effect on survival rate in patients with stage I-II of NSCLC.

Several studies of foreign authors state that the usage of single marker for prediction is less accurate than the use of combination of factors [14]-[16]. We have also observed that prediction through multivariate analysis was more accurate than the use of prognostic factor. It is necessary to use forecasting regression model in order to predict survival rate in patients with the early stage of NSCLC. It allows selecting patients with dismal prognosis. 
The future researches of conducting adjuvant polychemotherapy in this category of patients are necessary.

Cox-regression model with tumor size, histological type of tumor, volume of surgical intervention, volume of lymph node dissection, Ki-67 expression, EGFR expression and E-cadherin expression, could be useful for forecasting of survival rate in patients with stage I-II of NSCLC.

\section{References}

[1] Chen, D.-T., Hsu, Y.-L., William, J.F., et al. (2011) Prognostic and Predictive Value of a Malignancy-Risk Gene Signature in Early-Stage Non-Small Cell Lung Cancer. Journal of the National Cancer Institute, 103, 1859-1870. http://dx.doi.org/10.1093/jnci/djr420

[2] D’Amico, T.A., Massey, M., Herndon, J.E., et al. (1999) A Biologic Risk Model for Stage I Lung Cancer: Immunohistochemical Analysis of 408 Patients with the Use of Ten Molecular Markers. The Journal of Thoracic and Cardiovascular Surgery, 117, 736-743. http://dx.doi.org/10.1016/S0022-5223(99)70294-1

[3] Konopa, K. (2010) Do We Have Markers to Select Patients for Adjuvant Therapies of Non-Small-Cell Lung Cancer? Annals of Oncology, 7, vii199-vii202.

[4] Park, S.Y., Lee, H.-S., Jang, H.-J., et al. (2011) Tumor Necrosis as a Prognostic Factor for Stage IA Non-Small Cell Lung Cancer. The Annals of Thoracic Surgery, 91, 1668-1673. http://dx.doi.org/10.1016/j.athoracsur.2010.12.028

[5] Zhu, C.-Q., Shih, W., Ling, C.-H. and Tsao, M.-S. (2006) Immunohistochemical Markers of Prognosis in Non-Small Cell Lung Cancer: A Review and Proposal for a Multiphase Approach to Marker Evaluation. Journal of Clinical Pathology, 59, 790-800. http://dx.doi.org/10.1136/jcp.2005.031351

[6] Raz, D.J., Ray, M.R., Kim, J.Y., et al. (2008) A Multigene Assay Is Prognostic of Survival in Patients with Early-Stage Lung Adenocarcinoma. Clinical Cancer Research, 14, 5565-5570. http://dx.doi.org/10.1158/1078-0432.CCR-08-0544

[7] Harpole Jr., D.H., Herndon, J.E., Wolfe, W.G., et al. (1995) A Prognostic Model of Recurrence and Death in Stage I Non-Small Cell Lung Cancer Utilizing Presentation, Histopathology, and Oncoprotein Expression. Cancer Research, 55, 51-56.

[8] Holdenrieder, S., Nagel, D., Heinemann, V., et al. (2008) Predictive and Prognostic Biomarker Models in Advanced Lung Cancer. Journal of Clinical Oncology, 26, 19010.

[9] López-Encuentra, A., López-Ríos, F., Conde, E., et al. (2011) Composite Anatomical-Clinical-Molecular Prognostic Model in Nonsmall Cell Lung Cancer. European Respiratory Journal, 37, 136-142. http://dx.doi.org/10.1183/09031936.00028610

[10] Lang, T.A., Math, M.S. and Leonov, V.P. (2011) How to Describe the Statistics in Medicine. An Annotated Guide for Authors, Editors and Reviewers. M:, 480.

[11] Lu, C., Soria, J.-C., Tang, X., et al. (2004) Prognostic Factors in Resected Stage I Non-Small-Cell Lung Cancer: A Multivariate Analysis of Six Molecular Markers. Journal of Clinical Oncology, 22, 4575-4583. http://dx.doi.org/10.1200/JCO.2004.01.091

[12] Van der Pijl, L.L.R., Birim, O., Van Gameren, M., et al. (2010) Validation of a Prognostic Model to Predict Survival after Non-Small-Cell Lung Cancer Surgery. European Journal Cardio-Thoracic Surgery, 38, 615-620. http://dx.doi.org/10.1016/j.ejcts.2010.03.028

[13] Rubio, L., Vera-Sempere, F.J., Lopez-Guerrero, J.A., et al. (2005) A Risk Model for Non-small Cell Lung Cancer Using Clinicopathological Variables, Angiogenesis and Oncoprotein Expression. Anticancer Research, 25, 497-504.

[14] Dosaka-Akita, H., Hommura, F., Mishina, T., et al. (2001) A Risk-Stratification Model of Non-Small Cell Lung Cancers Using Cyclin E, Ki-67, Andrasp21: Different Roles of G1 Cyclins in Cell Proliferation and Prognosis. Cancer Research, 61, 2500-2504.

[15] Hilbe, W., Dirnhofer, S., Oberwasserlechner, F., et al. (2003) Immunohistochemical Typing of Non-Small Cell Lung Cancer on Cryostat sections: Correlation with Clinical Parameters and Prognosis. Journal of Clinical Pathology, 56, 736-741. http://dx.doi.org/10.1136/jcp.56.10.736

[16] Williams, B.A., Sugimura, H., Endo, C., et al. (2006) Predicting Postrecurrence Survival among Completely Resected Nonsmall-Cell Lung Cancer Patients. The Annals of Thoracic Surgery, 81, 1021-1027.

http://dx.doi.org/10.1016/j.athoracsur.2005.09.020 


\section{Abbreviatios}

ANOVA-Analysis of Variance

BMI-Body Mass Index

CI-Confidence Interval

CYFRA-Cytokeratin Fragment

DAPK-Death-Associated Protein Kinase

EGFR-Epidermal Growth Factor Receptor

NSCLC_Non-Small Cell Lung Cancer

OR-Odds Ratio 